\title{
Phosphorylation in intrinsically disordered regions regulates the activity of Neurogenin2
}

\author{
Gary S McDowell ${ }^{1,3^{*}}$, Christopher J Hindley ${ }^{1,4}$, Guy Lippens ${ }^{2}$, Isabelle Landrieu² and Anna Philpott ${ }^{* *}$
}

\begin{abstract}
Background: Neuronal differentiation is largely under the control of basic Helix-Loop-Helix (bHLH) proneural transcription factors that play key roles during development of the embryonic nervous system. In addition to well-characterised regulation of their expression, increasing evidence is emerging for additional post-translational regulation of proneural protein activity. Of particular interest is the bHLH proneural factor Neurogenin2 (Ngn2), which orchestrates progression from neural progenitor to differentiated neuron in several regions of the central nervous system. Previous studies have demonstrated a key role for cell cycle-dependent multi-site phosphorylation of Ngn2 protein at Serine-Proline (SP) sites for regulation of its neuronal differentiation activity, although the potential structural and functional consequences of phosphorylation at different regions of the protein are unclear.

Results: Here we characterise the role of phosphorylation of specific regions of Ngn2 on the stability of Ngn2 protein and on its neuronal differentiation activity in vivo in the developing embryo, demonstrating clearly that the location of SP sites is less important than the number of SP sites available for control of Ngn2 activity in vivo. We also provide structural evidence that Ngn2 contains large, intrinsically disordered regions that undergo phosphorylation by cyclin-dependent kinases (cdks).

Conclusions: Phosphorylation of Ngn2 occurs in both the N- and C-terminal regions, either side of the conserved basic Helix-Loop-Helix domain. While these phosphorylation events do not change the intrinsic stability of Ngn2, phosphorylation on multiple sites acts to limit its ability to drive neuronal differentiation in vivo. Phosphorylated regions of Ngn2 are predicted to be intrinsically disordered and cdk-dependent phosphorylation of these intrinsically disordered regions contributes to Ngn2 regulation.
\end{abstract}

Keywords: Phosphorylation, Intrinsic disorder, Protein NMR, Xenopus laevis, Neurogenin, Protein stability, Transcription factor, bHLH proteins, Protein folding

\section{Background}

During normal embryonic development, the tight regulation of cell fate decisions is absolutely required and differentiated phenotype is generally conferred by the transcription factor profile. In some cases a complete change of cellular identity can be driven by ectopic expression of one or a combination of such factors. For instance, fibroblasts can be reverted to pluripotency by introduction of the transcription factors Oct4, Sox2, Klf4

\footnotetext{
* Correspondence: Gary.McDowell@tufts.edu; ap113@cam.ac.uk 'Department of Oncology, MRC/Hutchison Research Centre, University of Cambridge, Cambridge Biomedical Campus, Cambridge CB2 OXZ, UK ${ }^{3}$ Current address: Center for Regenerative and Developmental Biology, Department of Biology, Tufts University, 200 Boston Avenue, Medford, MA 02155, USA

Full list of author information is available at the end of the article
}

and c-Myc [1]. Studies have also highlighted the potential of the basic Helix-Loop-Helix (bHLH) family of transcription factors to induce fate reprogramming of mature cells, converting cells from one differentiated phenotype into another: for example, exogenous MyoD is capable of reprogramming mouse fibroblasts to myocytes [2], and Ngn3, Pdx1 and MafA can convert liver cells into pancreatic beta cells in vivo [3]. While transcription factor expression and activity can be manipulated in vitro and in vivo to generate cells of a specific phenotype, it is clear that in vivo such transcription factor networks are tightly regulated to maintain phenotypic stability, and prevent inappropriate activation that might lead to dysregulation of the maintenance of cell fate. Whilst most efforts have focused on elucidating regulation of lineage-specific transcription factors at the 
level of gene expression, emerging evidence increasingly points to post-translational modification as a key regulator of transcriptional networks in response to the cellular environment [4].

Neurogenin2 (Ngn2) is a bHLH transcription factor that regulates the transition from neural progenitor to differentiating neuron. For instance, Ngn2 is involved in the formation of sensory neurons from the epibranchial placode [5] and neurogenesis in dorsal root ganglia [6], where it acts to determine the fate of progenitor cells as neuronal precursors and also to repress glial cell fates using separate mechanisms $[7,8]$. Furthermore, cell cycle exit and cell motility are regulated by Ngn2 [9], while experimentally, differentiation of neural stem cells can be induced by transfection of Ngn2 [10,11]. To undertake these roles, Ngn2 acts to upregulate a large number of downstream targets, including a cascade of additional bHLH transcription factors, such as NeuroD, as well as structural and functional genes associated with mature neuronal activity [12]. For transcriptional activity at its targets, Ngn2 has an obligate heterodimeric DNA binding partner, E12/E47, and this heterodimer binds to DNA, recruiting transcriptional coactivators such as $\mathrm{p} 300 / \mathrm{CBP}$ and Brg1 to facilitate target upregulation $[13,14]$. However, Ngn2 is expressed in neural progenitor cells prior to their differentiation [5], implying that its neurogenic activity must be suppressed until a permissive environment exists. Such regulation is likely to occur at the level of post-translational control of protein activity, which in turn is likely to be both dependent on and a regulator of protein tertiary and quaternary structure, although the higher order structure of Ngn2 is poorly characterised.

Proteins carry out various roles in the cell as a function of their structure. Enzymes require specific active site conformations in order to carry out catalysis and structural proteins require particular conformations to achieve mechanical strength. However it has become apparent that many functional proteins are, in fact, not natively folded at all times in the cell [15]. Proteins that are natively unfolded and lacking regular structure are termed intrinsically disordered (ID) proteins [16]. ID proteins show a lack of hydrophobicity [17] and extreme isoelectric point (pI) values due to a large net charge from a high prevalence of charged residues (see Table one in Weinreb et al., [18]). It has also been suggested that there is an increased rate of evolution in ID segments and proteins [19]. Therefore it may be that in these regions there is a lack of function allowing unconstrained mutation; or perhaps the function of the protein requires disorder itself and so a lack of evolutionary constraint on specific sequence allows a larger amount of variability. An investigation of the gene ontology terms associated with ID proteins highlights a significant number of proteins that are involved in DNA-binding, transcription activation and that act as transcription factors [20]. In these cases, intrinsic disorder would appear to regulate proteinprotein and protein-nucleic acid binding interactions, as thermodynamically this gives flexibility to signaling processes and the assembly of complexes in the cell. The free energy of binding is counteracted by the free energy required to fold the structure and so overall there is only a small free energy change [21].

While such a small free energy change would be predicted to allow only a low affinity of binding, there is a trade-off achieved with high specificity, through a requirement for the correct binding interactions and easy reversibility [22]. So small are the energy differences involved, that this may result in minor changes to the structure of a protein, but dramatic alterations to the formation of multifactor complexes. For example, this may allow fine tweaking of transcription dynamics, to form promoter complexes with DNA-binding cycles of various time periods leading to differential activation of various downstream targets $[23,24]$. ID proteins exhibit less transcriptional noise in expression than structured proteins and so appear to be tightly regulated at the point of their destruction [25], which also may further lead to tight control of downstream target gene expression. There is a high correlation between specific amino acid composition of ID proteins and phosphorylation sites, suggesting that phosphorylation may be promoted in disordered regions [26]. Furthermore, ID proteins are targeted by twice as many kinases as structured proteins [25]. Many of those kinases whose substrates are mainly unstructured proteins also tend to be regulated in a cell cycle-dependent manner [25].

Ngn2 exhibits some of the features common to ID proteins: there are a large number of charged residues leading to a low level of hydrophobicity [27] and the protein runs at a higher molecular mass (around $36 \mathrm{kDa}$ ) than its predicted molecular mass $(23.4 \mathrm{kDa})$ [18]. Ngn2 also shares many similarities with ID proteins with regard to amino acid composition [27], function [20] and stabilization upon the binding of other cofactors [28,29]. bHLH proteins show significant sequence homology in the bHLH domain only [30] and large sequence variability in the flanking regions, as is found in the evolutionary comparison of related ID proteins [19], again indicating the potential for large disordered regions in Ngn2. There is no published structural information for Ngn2 but a limited number of crystal structures are available for bHLH family homologues such as MyoD and NeuroD, bound to E47 as a heterodimer to DNA [31,32]. bHLH protein crystal structures exclude the $\mathrm{N}$ - and $\mathrm{C}$-terminal regions outside of the bHLH domain [31], as these regions are predicted to be disordered and thus will reduce the ability to purify, and therefore crystalise, the protein [33].

The stability of many bHLH proteins is regulated by phosphorylation events, e.g. MyoD [34]. Our previous work has highlighted that Ngn2 is a highly unstable 
protein [28,35-37], which appears to be highly phosphorylated in a cell cycle-dependent manner at serine-proline (SP) sites [38,39]. The relationship between the stability of Ngn2 and its phosphorylation status has been only briefly explored previously $[28,38]$ but a direct link between phosphorylation at SP sites and the stability of Ngn2 has not been investigated. In this work we explore the effects of phosphorylation at specific SP sites of Ngn2 on the activity and structure of the protein. We find that phosphorylation of Ngn2 has no significant effect on its intrinsic stability. Mutation of phosphorylation sites in both the $\mathrm{N}$ - and $\mathrm{C}$-terminal regions contributes to enhanced Ngn2 neuronal differentiation activity and further mutational analysis confirms that it is the number, and not position, of phosphorylation sites available that controls protein activity in vivo. Finally, we also present the first structural validation by NMR of full-length Ngn2 protein, and directly demonstrate phosphorylation in the $\mathrm{N}$-terminal region of mNgn2 by NMR spectroscopy.

\section{Results}

Mutation of conserved and non-conserved SP phosphorylation sites does not significantly alter Ngn2 protein half-life in vitro

If specific phosphorylation sites act to regulate Ngn2 activity then we would expect such sites to be highly conserved across species, in line with the conservation of Ngn2 function. All available NCBI Ngn2 protein sequences were aligned using the Clustal W2 multiple sequence alignment tool (Additional file 1: Figure S1), and compared to Xenopus laevis Ngn2 (xNgn2), where multi-site phosphorylation and stability have been best characterised [28,35-39]. The Ngn2 bHLH domain was defined by homology to the MyoD and NeuroD bHLH domains as lying between glycine 72 and leucine 139 of the xNgn2 sequence ([30], Additional file 1: Figure S1, green box). Compared to human Ngn2 (hNgn2), the sequence most divergent from $\mathrm{xNgn} 2$, the $\mathrm{xNgn} 2 \mathrm{bHLH}$ domain shows $84 \%$ conservation and $99 \%$ similarity and thus appears to be highly conserved, in agreement with previously published studies (reviewed in [30]). By contrast, the N-terminal region of xNgn2 shows $24 \%$ conservation and $70 \%$ similarity and the $\mathrm{C}$-terminal region of $\mathrm{xNgn} 2$ shows $31 \%$ conservation and $74 \%$ similarity to $\mathrm{hNgn} 2$. The $\mathrm{N}$ - and C-terminal regions are therefore not as highly conserved as the bHLH domain but both show a similar extent of conservation compared to each other.

Ngn2 has previously been shown to be phosphorylated on serines of serine-proline (SP) sites [38,39], while threonine-proline (TP) sites may also be potential sites of phosphorylation. There are no SP or TP sites present in the bHLH domain of any species. Surprisingly, given the poor conservation of sequence overall, three of the four SP sites (serines 172, 181 and 184) in the C-terminal region of xNgn 2 are highly conserved with all other species whilst the other SP site is close in the primary sequence to a site conserved in other species. These sites include the two residues identified as glycogen synthase kinase $3 \beta$ (GSK3 $\beta$ ) phosphorylation sites in mNgn2 [40]. By contrast, despite the presence of 5 SP sites in the Nterminal region of $\mathrm{xNgn} 2$, a highly conserved SP site is seen in the $\mathrm{N}$-terminal region of other species but this is not conserved in $x$ Ngn2. Although we have previously shown that in general it is the number of SP site phosphorylation events that is critical for regulating Ngn2 function in vitro rather than their precise location $[38,39]$, nevertheless, the conservation of SP site locations raises the possibility that SP or TP phosphorylation sites in the C-terminal region may be particularly important for the regulation of Ngn2 function. We have explored this possibility here by investigating further the protein stability and function of xNgn2 mutants where specific combinations of SP sites are mutated to prevent their phosphorylation.

To assess the role of SP site phosphorylation in the regulation of Ngn2 stability and function, we generated mutant versions of $\mathrm{xNgn} 2$ in which either $\mathrm{N}$ - or C-terminal region SP sites were mutated to Alanine-Proline (AP) to generate NT-S-AxNgn2 and CT-S-AxNgn2, respectively (see Additional file 2: Figure S2 for a summary of SP site mutants used). We first analysed protein stability in mitotic Xenopus egg extracts that have been previously shown to maximally phosphorylate Ngn2 at SP sites [38]. NT-S-AxNgn2 and CT-S-AxNgn2 protein stabilities were compared to those of wild-type $\mathrm{xNgn} 2$ and a mutant version of $\mathrm{xNgn} 2$ in which all SP sites are mutated to AP and which demonstrates a dramatically increased neuronal differentiation activity in vivo in Xenopus frog embryos (9S-AxNgn2, see Additional file 2: Figure S2 and [38]).

To investigate the effect of mutation of $\mathrm{N}$ - and Cterminal region SP sites on protein stability, ${ }^{35} \mathrm{~S}$-radiolabelled in vitro translated (IVT) xNgn2, 9S-AxNgn2, NT-S-AxNgn2 and CT-S-AxNgn2 were added to Xenopus mitotic egg extract and samples removed at increasing timepoints. Proteins were separated by 15\% SDS-PAGE and subjected to autoradiography to allow measurement of protein levels over time and calculation of the half-life for degradation using first-order rate kinetics (Figure 1A) $[28,35]$. In this assay, $x N g n 2$ had a half-life of $33.0+/-2.1$ mins. Although the trend is towards increased stability, 9S-AxNgn2 shows no statistically significant difference compared to wild-type Ngn2, with a half-life of $55.9+/-$ 10.0 mins. NT-S-AxNgn2 has a half-life of $28.5+/-2.8$ mins, while CT-S-AxNgn2 has a half-life of $74.4+/-20.3$ mins. Both mutant versions therefore tend towards increased stability compared to wild-type $\mathrm{xNgn} 2$, but again variability in repeat assays means that no statistically significant difference in stability was observed. 


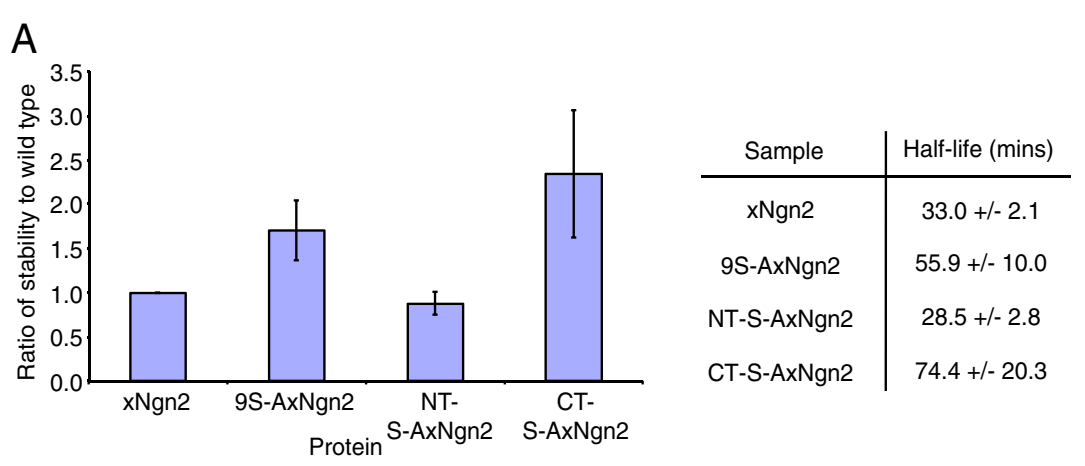

B

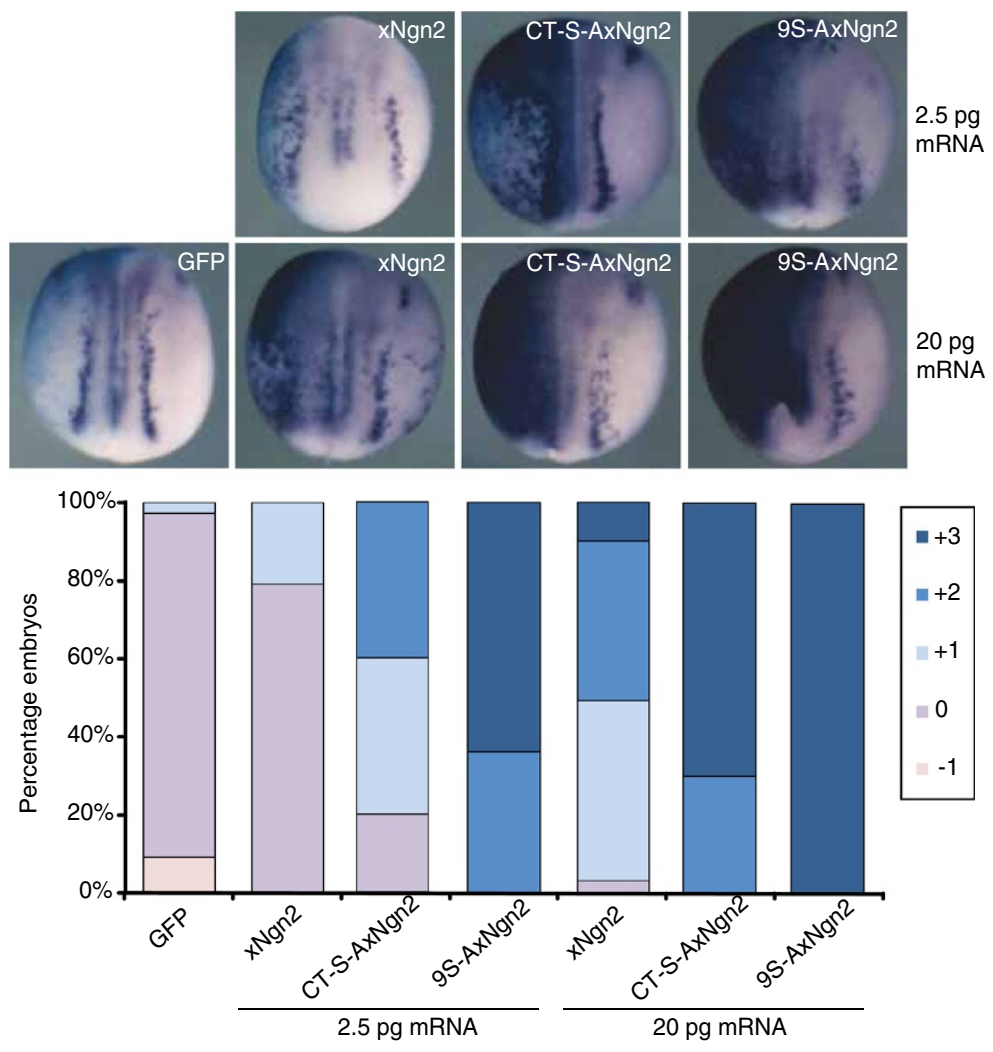

C

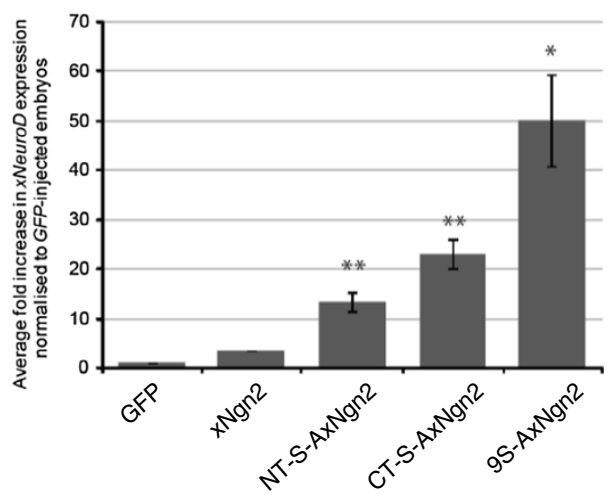

Figure 1 (See legend on next page.) 
(See figure on previous page.)

Figure 1 Phosphorylation at SP sites in both the $\mathbf{N}$ - and C-terminal regions regulates xNgn2 activity. (A) ${ }^{35} \mathrm{~S}-\mathrm{labelled} \mathrm{IVT} \times \mathrm{Ngn} 2$, or the indicated Serine-Proline to Alanine-Proline xNgn2 mutants, full phosphomutant (9S-AxNgn2), N-terminal region (NT-S-AxNgn2) or C-terminal region (CT-S-AxNgn2), were added to Xenopus laevis mitotic egg extracts and incubated at $21^{\circ} \mathrm{C}$. Samples were taken at 0, 15, 30, 45, $60,75,90$ and 120 mins and separated on 15\% SDS-PAGE gels. Gels were analyzed by quantitative phosphorimaging analysis, calculating the average stabilization relative to wild-type xNgn2 within mitotic extract. Half-lives were calculated using first-order rate kinetics, and errors calculated using the Standard Error of the Mean (SEM). (B) Embryos were injected into 1 cell of 2 cells with the indicated amount of mRNA encoding GFP, xNgn2, CT-S-AxNgn2 or 9S-AxNgn2, injected side to the left. Embryos were fixed at stage 15 and subjected to in situ hybridization for neural ß-tubulin expression before being scored for increased neurogenesis on the injected side compared to the uninjected side on a scale of 0-3 [38]. The experiment was performed in duplicate ( $n=17-37)$. (C) 1 cell-stage embryos were injected with 20 pg of mRNA encoding GFP, xNgn2, NT-S-AxNgn2, CT-S-AxNgn2 or 9S-AxNgn2, harvested at stage 15 and expression of xNeuroD analysed by qPCR ( 5 embryos per sample, $n=3$ ).

Therefore, we have directly demonstrated that phosphorylation status of Ngn2 does not directly control its stability in Xenopus.

\section{SP sites in both the $\mathrm{N}$ - and $\mathrm{C}$-terminal regions regulate the activity of $\mathrm{xNgn} 2$}

Previous work has indicated that preventing xNgn2 phosphorylation on all 9 SP sites enhances its ability to drive neuronal differentiation in vitro and in vivo $[38,39]$. We have observed phosphorylation of $\mathrm{xNgn} 2$ at SP sites in both the $\mathrm{N}$ - and $\mathrm{C}$-terminal regions following incubation in Xenopus mitotic egg extract [38]. Assaying the activity of a sequential mutant series of mouse Ngn2 (mNgn2) where SP sites were additively mutated from the Cterminus (mutating the first $\mathrm{C}$-terminal SP in mutant 1 , the first and second in mutant 2, the first, second and third in mutant 3 etc.) showed an incremental increase in neuronal differentiation activity in vitro with the loss of each additional SP site [38,39]. In addition, analysis of the in vivo neuronal differentiation activity of a single SP site knock-in series allowed us to determine that phosphorylation at individual SP sites could not account for regulation of the neuronal differentiation activity of $x \operatorname{Ngn} 2$ [38]. However, these analyses did not allow us to determine the contribution of the $\mathrm{N}$ - and C-terminal region SP sites to the phospho-regulation of the neuronal differentiation activity of mNgn2, nor whether one region played a more prominent regulatory role than the other. mNgn2 has only two N-terminal SP sites and previous assays [38] showed in fact that their mutation had a minimal effect on the differentiation of P19 cells, which respond to overexpression of proneural proteins by undergoing neuronal differentiation [41]. This points to increased prominence for Cterminal phosphorylation events for Ngn2 regulation. However, it was unclear whether the mNgn2 N-terminal SP sites had only minimal effects on the neuronal differentiation-inducing ability of Ngn2 because there are only two of them or because phosphorylation of sites in the N-terminus of Ngn2 plays an intrinsically lesser role in regulating Ngn2 activity than phosphorylation of sites in the C-terminus for domain structure/function reasons. By contrast to $\mathrm{mNgn} 2, \mathrm{xNgn} 2$ has five SP sites in the N- terminus. We investigated whether the larger number of potential phosphorylation sites in $\mathrm{xNgn} 2$ compared to mNgn2 results in a greater contribution of N-terminal phosphorylation to regulation of $\mathrm{xNgn} 2$ activity relative to $\mathrm{mNgn} 2$, or whether N-terminal phosphorylation, regardless of number of sites available, plays little role in phosphoregulation of the neuronal differentiation activity of Ngn2 protein.

To assess whether preventing phosphorylation at the conserved SP sites in the C-terminus of $\mathrm{xNgn} 2$ alone was sufficient to maximally activate the protein, we compared the neuronal differentiation activity of xNgn2, CTS-AxNgn2 and 9S-AxNgn2 in vivo in Xenopus embryos. To this end, mRNAs encoding xNgn2, CT-S-AxNgn2 and $9 \mathrm{~S}-\mathrm{AxNgn} 2$ were generated and overexpressed in 1 cell of 2 cell Xenopus embryos, and an assessment of ectopic neurogenesis was performed as previously described, comparing the injected and the uninjected side [38]. As expected, 9S-AxNgn2 had significantly higher neuronal differentiation activity than wild-type $\mathrm{xNgn} 2$ $[38,39]$. The overexpression of CT-S-AxNgn2 resulted in a level of ectopic neurogenesis intermediate between that of overexpressed wild-type xNgn2 and 9S-AxNgn2 (Figure 1B), indicating that phosphorylation on the Nterminus of $\mathrm{xNgn} 2$ does indeed contribute to limiting $x N g n 2$ neuronal differentiation activity. To further investigate the neuronal differentiation activity of the mutants in vivo, we then quantified the expression of the direct downstream $x$ Ngn2 target $x$ NeuroD by qRT-PCR in response to overexpression of $x$ Ngn2, NT-S-AxNgn2, CT-S-AxNgn2 and 9S-AxNgn2 in 1 cell-stage Xenopus embryos (Figure 1C). Both NT-S-AxNgn2 and CT-SAxNgn2 showed an intermediate neuronal differentiation activity between that of $\mathrm{xNgn} 2$ and 9S-AxNgn2, demonstrating that phosphorylation at SP sites in both the $\mathrm{N}$ - and C-terminal regions of $\mathrm{xNgn} 2$ contributes to regulating its transcriptional activity. Therefore, in addition to our previous work highlighting the importance of the number of SP sites for regulation of neuronal differentiation activity, we show clearly here that SP sites in both the $\mathrm{N}$ - and C-terminal domains can contribute to regulation of protein function. 
In vivo activity of $\mathrm{xNgn} 2$ is a semi-quantitative measure of phospho-site availability

P19 embryonal carcinoma cells respond to ectopic Ngn2 expression by undergoing neuronal differentiation in vitro [41]. Our previous data in P19 cells with a cumulative phospho-mutant series of $\mathrm{mNgn} 2$ proteins (where SP sites are additively mutated from the C-terminus: mutant 1 , most C-terminal SP site mutated, mutant 2, the two SP sites nearest the $\mathrm{C}$-terminus are mutated, etc.) had suggested that the number of SP sites available for phosphorylation act semi-quantitatively to regulate the neuronal differentiation activity of Ngn2 [38,39]. The results presented above support the hypothesis that phosphoregulation of Ngn2 is not strictly dependent on the position or level of conservation of the SP site that is modified but rather on the number of SP sites available. To confirm this in vivo, we overexpressed a cumulative phospho-mutant series of $\mathrm{xNgn} 2$ proteins, this time where SP sites were additively mutated from the $\mathrm{N}$-terminus (mutant 1 , most $\mathrm{N}$ terminal SP site mutated, mutant 2, the two SP sites nearest the N-terminus are mutated, etc.; Additional file 2: Figure $\mathrm{S} 2$, as opposed to mutation from the C-terminus for mNgn2 as described above [38]), in 1 cell of 2 cell Xenopus embryos, to semi-quantitatively assay the multi-site phospho-regulation of $\mathrm{xNgn} 2$ 's neuronal differentiation activity in vivo. Embryos were subjected to in situ hybridization for neural $\beta$-tubulin expression and the injected and uninjected sides compared as above (Figure 2). As additional SP sites were mutated from the N-terminus, we saw that the neuronal differentiation activity of the mutant xNgn2 proteins progressively increased, finally reaching maximal activity when all 9 SP sites were mutated in 9S-AxNgn2. Strikingly, when taken with data demonstrating a gradual increase in mNgn2 activity in P19 cells in vitro as SP sites are cumulatively mutated from the C-terminus [38], these data demonstrate conclusively that the precise location of SP sites is not of major importance for the phospho-regulation of Ngn2 activity, but rather it is the number of SP sites available for modification that is critical for controlling Ngn2 activity in vivo and in vitro. Compared to our previous data showing the effect of serial loss of SP sites from the Cterminal end of the protein in vitro, we now show, in vivo, that the reciprocal mutation series from the $\mathrm{N}$-terminus of the protein behaves in a similar way. We can clearly now demonstrate that it is neither specific SP sites, nor their location in a particular protein domain, but rather it is the absolute number of phosphorylation sites, that determines Ngn2 protein activity.

\section{Ngn2 proteins are predicted to be intrinsically disordered outside the bHLH domain}

The results presented above, taken together with data in [38] and [39], strongly support the hypothesis that the ability of $\mathrm{xNgn} 2$ to drive neuronal differentiation is regulated by modification on multiple SP sites and that it is the number of SP sites available for modification and not their position that is the prime determinant of neuronal differentiation activity. Structural consequences of phosphorylation could suggest a molecular mechanism for the multi-site phospho-regulation of Ngn2 activity but the structure of phosphorylated regions of Ngn2 has not been explored.

By analogy with other bHLH proteins, it seems very likely that the $\mathrm{N}$ - and C-terminal regions of Ngn2 are intrinsically disordered. Ngn2 exhibits some of the features of ID proteins: there are a large number of charged residues leading to a low level of hydrophobicity [27]; and the protein runs at a higher molecular mass (around $36 \mathrm{kDa}$ ) than its calculated molecular mass (23.4 kDa) [18]. Computational analysis of the extent of protein disorder using PONDR-FIT (available from www.DisProt.org/pondr-fit. php [42]), predicts a high degree of disorder in the $\mathrm{N}$ - and C-terminal regions of Xenopus (Figure 3A) and mouse (Figure 3B) Ngn2, with a highly ordered section in the middle of the sequence corresponding to the bHLH domain. Both Xenopus and mouse Ngn2 exhibit low sequence conservation in the $\mathrm{N}$ - and $\mathrm{C}$-terminal regions (see above and Additional file 1: Figure S1) but these regions in both proteins are predicted to be similarly highly disordered (Figure 3A, B), Further disorder predictions were carried out with mouse Ngn2 in order to compare the results from various predictors.

DISOPRED2 (http://bioinf.cs.ucl.ac.uk/disopred/, [43]) is a prediction algorithm that has been developed using empirically determined standards from experimental datasets. DISOPRED2 predicts that mNgn2 contains highly disordered $\mathrm{N}$ - and C-terminal regions flanking a folded region (Figure $3 \mathrm{C}$ ), in agreement with the PONDR-FIT prediction (Figure 3B). FoldIndex (http://bip.weizmann. ac.il/fldbin/findex, [44]) uses the hydrophobicity and charge of the residues within the amino acid sequence to predict disordered regions and in agreement with the other algorithms, predicts disordered regions in $\mathrm{mNgn} 2$ at the $\mathrm{N}$ - and C-terminal regions interspaced by a folded region (Figure $3 \mathrm{D})$. However, compared to the previous predictions (Figure 3B, C), FoldIndex predicts the folded region to be shifted towards the $\mathrm{N}$-terminus and to be much larger. This correlates with the distribution of hydrophobic and charged residues in mNgn2 (Additional file 1: Figure S1). Therefore whilst Ngn2, and other bHLH proteins, may not be disordered across their entire length, empirical observations relating to the difficulties of protein purification [33], together with the disorder predictions for mNgn2 described above, suggest that intrinsically disordered regions are present.

NMR spectroscopy runs into a size problem for folded proteins because of increased tumbling time with concomitant enhanced line broadening of the signals [45]. By 


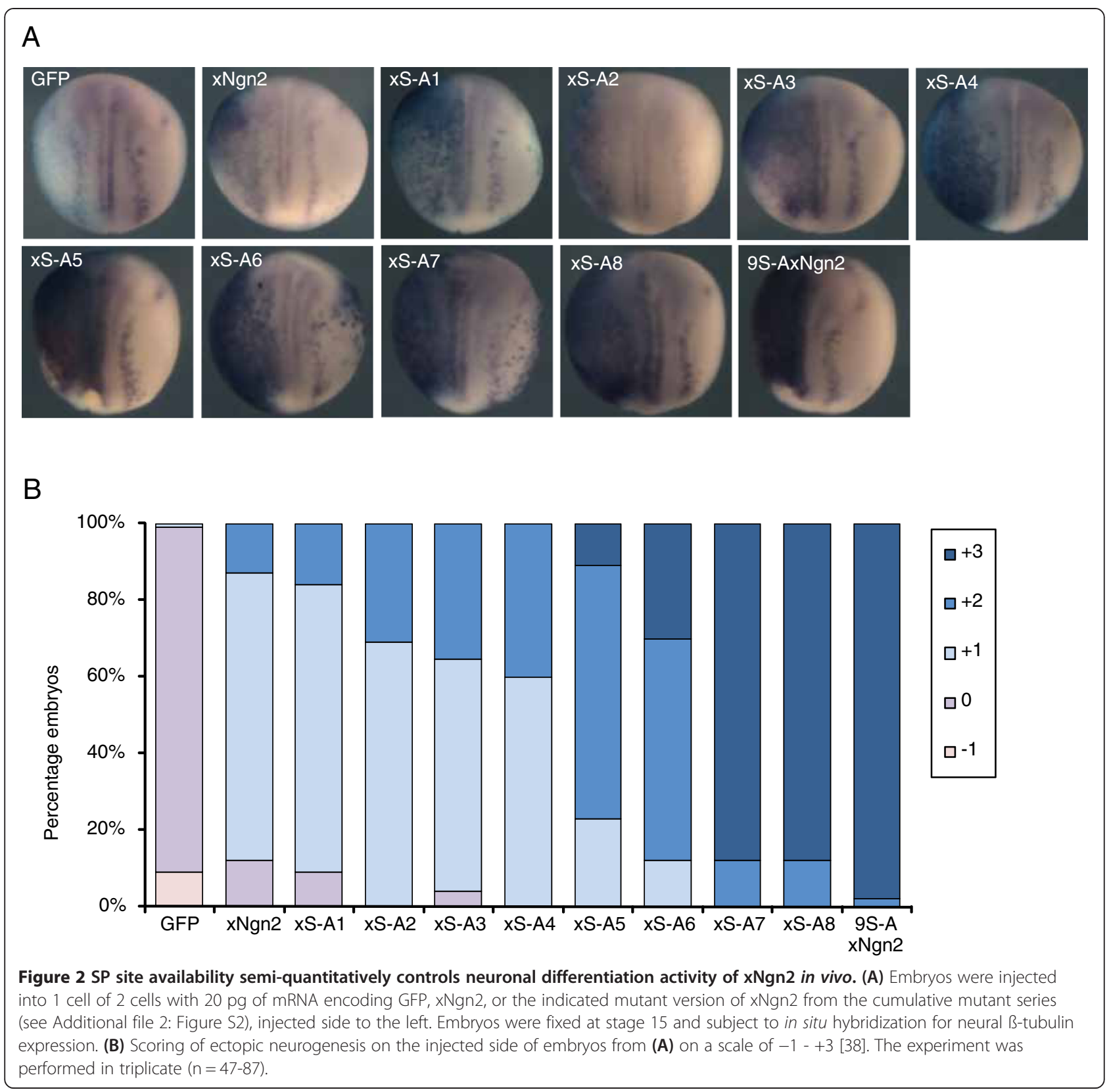

contrast, in ID proteins the fast molecular internal dynamics contribute to longer relaxation times compared to folded proteins of the same size, and result in narrow resonances that allow good detection and resolution [45]. Using this property of the NMR signal, we set out to determine whether we could detect the disordered regions of Ngn2 and phosphorylation events therein.

Characterization of mouse Ngn2 conformation in solution and mapping of mouse Ngn2 phosphorylation sites using NMR spectroscopy

In order to directly confirm SP or TP sites in mNgn2 as targets for phosphorylation and to obtain further information on its secondary structure, a bacterially-expressed GST-mNgn2 fusion protein was ${ }^{15} \mathrm{~N}$, or ${ }^{15} \mathrm{~N},{ }^{13} \mathrm{C}$ isotopically-labelled for NMR spectroscopy analysis. Mouse Ngn2 was chosen, as although both mouse and Xenopus Ngn2 have been wellcharacterized [38,39], previous attempts to purify Xenopus Ngn2 had been unsuccessful and it was hoped that mouse Ngn2, codon-optimized for bacterial expression, might prove more tractable (see Methods). Despite the limited solubility of full-length phosphorylated mNgn2 (see below), after cleavage of the GST carrier protein, we were still able to obtain a 2D ${ }^{1} \mathrm{H},{ }^{15} \mathrm{~N}$ HSQC spectrum with close to 100 resonances (Figure 4, Additional file 3: 2D NMR dataset). The poor dispersion of the signal on the ${ }^{1} \mathrm{H}$ scale indicates that the 

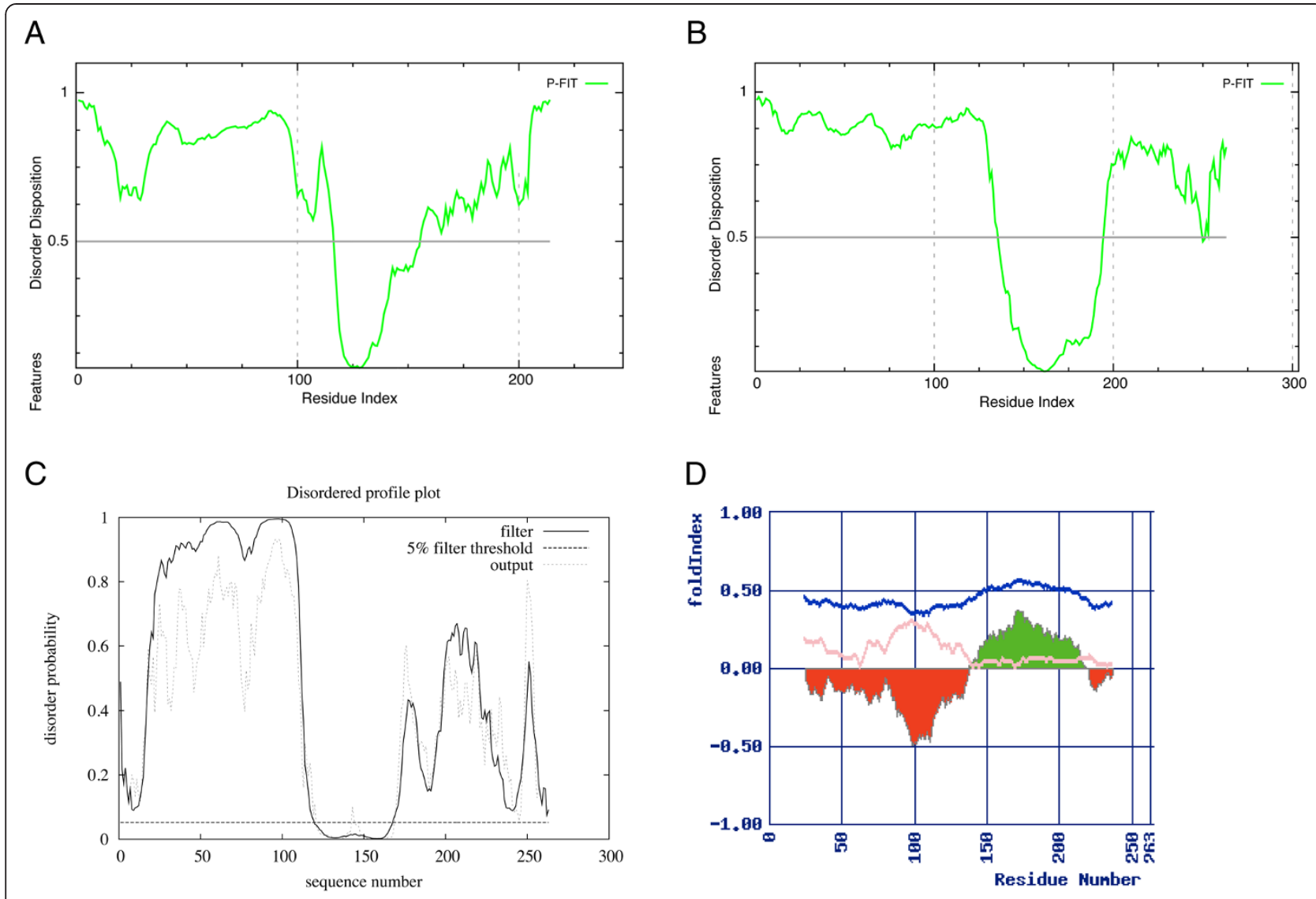

D

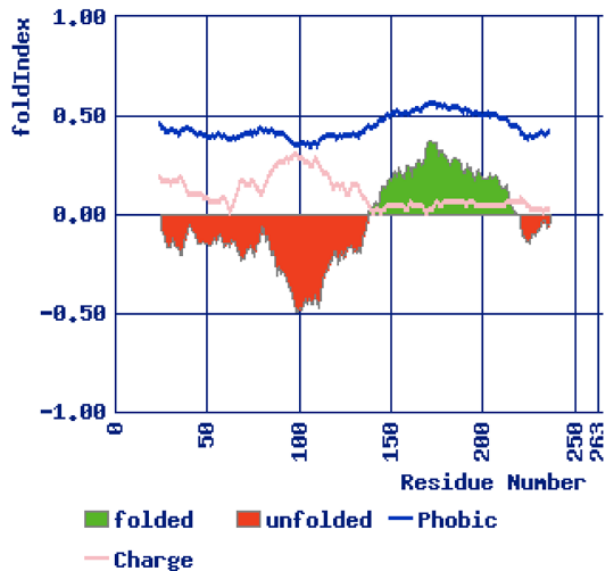

Figure 3 The terminal regions of $\mathrm{Ngn} 2$ are predicted to be intrinsically disordered. PONDR-FIT disorder predictions of (A) xNgn2 and (B) mNgn2. (C) DISOPRED2 and (D) Foldlndex disorder predictions of mNgn2.

detected regions are disordered in nature, confirming the primary sequence-based predictions (Figure 3).

To investigate phosphorylation events in its disordered regions, recombinant $\mathrm{mNgn} 2$ protein was phosphorylated in vitro by incubation with recombinant CyclinA/CDK2 kinase, which was previously shown to phosphorylate $\mathrm{xNgn} 2$ ([38] and unpublished data) and regulates xNgn2 activity in vivo [38]. Analysis of the phosphorylated forms of $\mathrm{mNgn} 2$ using 2D NMR spectroscopy showed 3 new resonances that were absent in the $2 \mathrm{D}$ spectrum of the unphosphorylated form of $\mathrm{mNgn} 2$, in the region expected for pSer and pThr residues (Figure 4A, Additional file 3: 2D NMR dataset).

Assignment of the backbone atom resonances of $\mathrm{mNgn} 2$ was performed based on $3 \mathrm{D}$ experiments on the ${ }^{15} \mathrm{~N},{ }^{13} \mathrm{C}$ doubly-labelled protein (Additional file 4: Table S1, Additional file 5: 3D NMR dataset). This assignment does not cover the full-length protein: the detected domains correspond to residues 1 to 31 and 49 to 75 , containing two SP sites and one TP site. Comparison with the secondary structure prediction based on the primary sequence confirms that these regions of the protein are located outside of the
bHLH domain and are not predicted to adopt stable secondary structures (Figure 3 and Additional file 1: Figure S1). Although these regions are disordered, closer examination of their chemical shifts by comparison with databases of chemical shifts of strictly random coil polymers [46] would suggest a local tendency to adopt transient secondary structure. Using the secondary structure propensity analysis, we observed a positive deviation of the experimental chemical shifts in segments aa15-20 and aa67-74 of the protein, consistent with the adoption of transient alpha-helical structure. However, a negative deviation in the $\mathrm{C}$-terminal region between aa49-56 is indicative of a tendency to adopt an extended conformation (Figure 4B). The phosphorylated sites therefore reside in regions of high intrinsic disorder.

We next used the carbon signals in the $3 \mathrm{D}$ experiments to identify the phosphorylated residues $[47,48]$. The CA and $\mathrm{CB}$ chemical shifts allow discrimination of a $\mathrm{pS}$ from a $\mathrm{pT}$ residue [49], while the CA- 1 and $\mathrm{CB}-1$ resonances will inform on the nature of the amino acid at the $\mathrm{N}$-terminus (Additional file 4: Table S1). Cdks are proline-directed kinases and a proline at the $\mathrm{i}+1$ position will alter the $\mathrm{CA}$ 
A

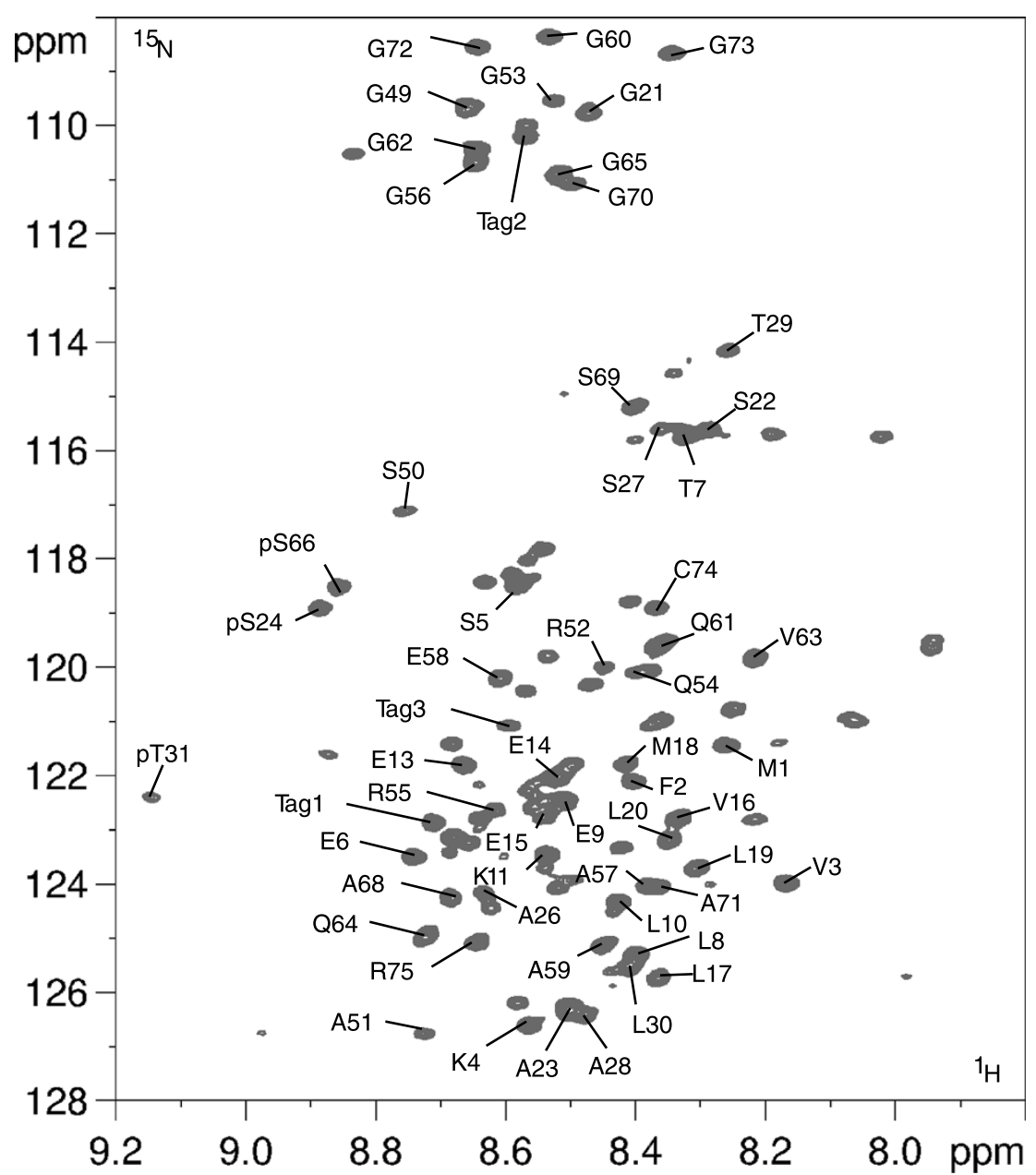

B

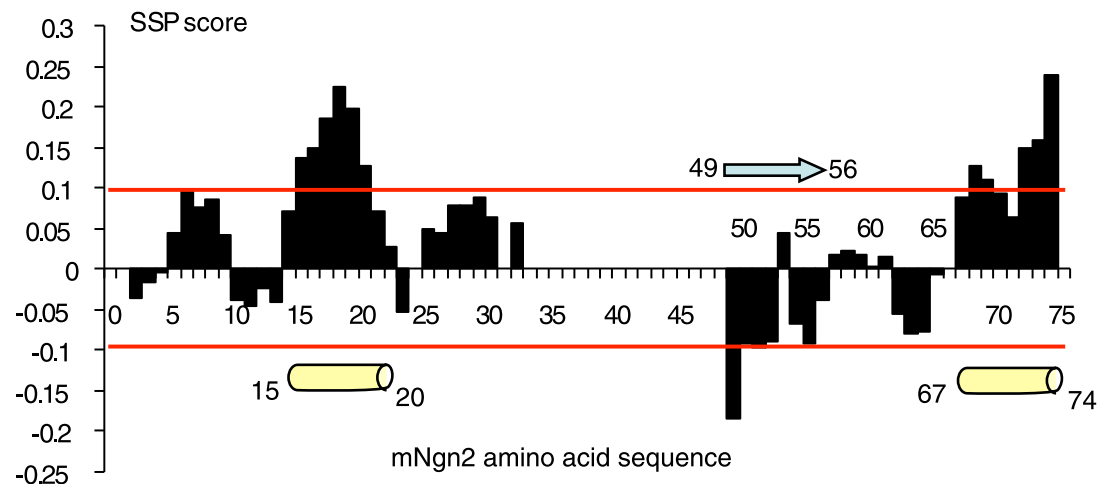

Figure 4 Annotated ${ }^{1} \mathrm{H},{ }^{15} \mathrm{~N} 2 \mathrm{D}$ spectra of phosphorylated ${ }^{15} \mathrm{~N}$-mNgn2 showing altered structural positions of phosphorylated residues. (A) Detail of overlayed 2D $\left[{ }^{1} \mathrm{H},{ }^{15} \mathrm{~N}\right] \mathrm{HSQC}$ spectra of ${ }^{15} \mathrm{~N}$ mNgn2 phosphorylated with cycA/CDK2. Resonances corresponding to phosphorylated Ser and Thr residues are labelled. (B) Secondary Structure Propensity (SSP, [46]) along the mNgn2 sequence calculated based on the available CA and CB chemical shifts (Additional file 4: Table S1). SSP scores correspond to a calculated percentage of occupancy: the 0.1/-0.1 thresholds, here represented as red lines, being empirically proposed for significance. Regions with positive values are associated with a preferential a-helical conformation, here presented as cylinders. Regions with negative values are associated with a preferential extended conformation, here presented as arrows. 
chemical shift by a $+2 \mathrm{ppm}$ deviation compared to the chemical shift expected for a pS or pT [50]. Phosphorylated residues were thus identified as pS24, pT31 and pS66, which are SP and TP sites conserved between $\mathrm{xNgn} 2$ and mNgn2 (Figure 4A and Additional file 1: Figure S1).

This is the first structural information obtained by NMR for full-length Ngn2 protein and it directly demonstrates the intrinsic disorder inherent to the protein, a characteristic of Ngn2 previously only predicted by using protein folding computational algorithms. In addition we have directly shown that protein phosphorylation in vitro can be mediated by cyclinA/CDK2 within the intrinsically disordered domain.

\section{Discussion}

Studies are revealing the remarkable plasticity of fully differentiated somatic cells when exposed to an exogenous set of transcription factors. From the now well established transcription factor cocktails that promote reprogramming to an induced pluripotent cell state [1] through to reprogramming to induced neurons [51], the power of specific transcription factor networks to determine cell fate even in the absence of the normal physiological environment or developmental stage is well accepted. However, such transcription factor networks must regularly be broken and replaced during embryonic development, implying a tight regulation of the transcription factors themselves and mechanisms for restraining their activities. Although posttranslational methods of regulation, such as phosphorylation and protein degradation, are beginning to be more widely investigated [4], mechanisms integrating different forms of post-translational regulation have been poorly studied. We have previously described regulation of the proneural bHLH transcription factor Ngn2 by both ubiquitin-mediated proteolysis and cell cycle-mediated phosphorylation at SP sites [28,35-39]. In this study, we have explored possible links between these modes of regulation and investigated in greater depth the regulation and structural consequences of Ngn2 by phosphorylation at SP sites.

By comparing the protein primary sequence of $\mathrm{xNgn} 2$ to homologues in other species (Additional file 1: Figure S1), it is clear that conservation of Ngn2 sequence outside of the bHLH domain is poor. Strikingly, however, conservation of SP sites in the C-terminal region is very high, and more so than the conservation of SP sites in the Nterminal region. As Ngn2 is a highly unstable protein, we investigated whether phosphorylation of these sites might influence protein half-life. Despite conservation, mutation of SP sites in the C-terminal region of $\mathrm{xNgn} 2$ had no significant effect on protein stability, nor did mutation of $\mathrm{N}$-terminal SP sites (Figure 1A), indicating that phosphorylation on these sites does not regulate the intrinsic stability of the protein. However, assays of stability in this in vitro system do not preclude the possibility that phosphorylation of Ngn2 could indirectly influence protein stability, for instance by affecting its ability to associate with binding partners not present in egg extract. Both $\mathrm{N}$ and C-terminal SP sites regulate the overall neurogenic activity of $\mathrm{xNgn} 2$ in vivo (Figure $1 \mathrm{~B}, \mathrm{C}$ ) but our data taken together indicate (as only suggested indirectly in previous work) that control of intrinsic protein stability is not the major mechanism by which phosphorylation at SP sites of xNgn2 acts to control neuronal differentiation activity.

We went on to expand upon our previous observations $[38,39]$ and to explore further whether the position of SP sites has a major influence on their ability to regulate the neuronal differentiation activity of xNgn2 by using phosphomutant Ngn2s in vivo in developing embryos. In contrast to mNgn2, where mutation of its two N-terminal SP sites did not significantly enhance its neurogenic activity in vitro in P19 cells, SP sites in both the $\mathrm{N}$ - and $\mathrm{C}$-terminal regions of $\mathrm{xNgn} 2$ contribute to regulation of its neuronal differentiation activity in vivo in Xenopus embryos (Figure 1B, C and [38]). Our previous observation in vitro that it is the number and not position of SP sites which is the determinant of Ngn2 neuronal differentiation activity [38] was confirmed in vivo in Xenopus embryos using a series of $x$ Ngn2 mutants in which SP sites had been cumulatively changed to AP sites, beginning from the N-terminus (cumulative SP site mutant series, see Additional file 2: Figure S2 for more information, Figure 2). These results, using assays of activity in vivo, clearly reinforce a model suggested by in vitro data [38] that it is the number, and not position, of phosphorylation events at SP sites in Ngn2 that regulate its neuronal differentiation activity.

As it is not the precise location but the number of phospho-sites available that regulates Ngn2 activity, this led us to consider whether structural plasticity associated with intrinsic disorder might facilitate such regulation. In this regard, previous studies suggested that these regions might be intrinsically disordered $[18,27,33]$. ID proteins show an increased rate of evolution in disordered regions and both Xenopus and mouse Ngn2 exhibit low sequence conservation in the $\mathrm{N}$ - and $\mathrm{C}$-terminal regions (Additional file 1: Figure S1).

The purification of bHLH proteins is problematic as illustrated by the work of Aguado-Lllera et al. [33]. The authors attempted to purify the bHLH domain of Ngn1 using His-tagged, GST-tagged, maltose binding proteintagged, biotin-tagged and thioredoxin-tagged protein constructs in BL21, Rosetta, C41 and BL21pLys cells with induction at several different temperatures and with varying concentrations of IPTG. Only one combination appeared to work at all but the protein was found to be partially degraded. The authors finally turned to chemical synthesis of the bHLH domain of Ngn1 instead. Indeed, bHLH protein crystal structure determination is usually performed on a protein devoid of the $\mathrm{N}$ - and C-terminal regions (i.e., regions outside of the bHLH domain [31]) as these regions have previously been predicted to be disordered. However, some evidence exists that even within the 
bHLH domain bound to both its heterodimeric binding partner and E-box DNA there is still a tendency towards disorder [33]. Disorder-predicting programs are based upon protein sequence information alone and the in vivo environment is not yet accurately reproducible in silico. Nevertheless, the predictions performed here (Figure 3) do correlate well for both Xenopus and mouse Ngn2 and suggest that a high degree of disorder is likely, particularly in the $\mathrm{N}$ - and $\mathrm{C}$-terminal regions. The FoldIndex prediction (Figure 3D) correlates least with the other predictions. However, FoldIndex places a greater bias upon the hydrophobicity and charge of the residues in the peptide sequence [44] and whilst this is usually a good predictor of intrinsic disorder [27] there may be circumstances under which it is insufficient.

To directly investigate the level of disorder within the regions of Ngn2, we attempted to purify $\mathrm{mNgn} 2$ and investigate its tertiary structure and phosphorylation by NMR. Unsurprisingly, the purification of $\mathrm{mNgn} 2$ proved to be difficult; previous attempts to purify $\mathrm{xNgn} 2$, using both bacterial expression and baculovirus systems had been largely unsuccessful (data not shown). Sarkosylbased treatment [52] resulted in the liberation of some His-mNgn2 from the insoluble fraction of the cell lysate. Solubility of the protein was greatly improved by using a GST-tag and we were able to isolate GST-mNgn2 from the soluble fraction instead (data not shown). Despite these difficulties, we were able to purify a sufficient quantity of protein to obtain unambiguous NMR spectra, although signals originate from only the N-terminal region of the protein. The NMR spectra for mNgn2 demonstrated that the $\mathrm{N}$-terminal region of the protein was disordered, and that serines 24 and 66 and threonine 31 are phosphorylated in vitro by cyclinA/CDK2 (Figure 4A). That the NMR results comprise spectra allowing the identification of phosphorylated SP and TP sites in the N-terminal region, conserved between $\mathrm{xNgn} 2$ and $\mathrm{mNgn} 2$, illustrates not only direct phosphorylation of SP sites by cyclinA/CDK2 in vitro but also that this occurs in the disordered $\mathrm{N}$-terminal region. This structural evidence for the disordered N-terminal domain, and the phosphorylation which modifies it, provide a direct demonstration of phosphorylation of Ngn2, and compliment previous work inferring phosphorylation by using extract systems in vitro and by using activity assays of phospho-mutant Ngn2 in vivo.

Our data demonstrate that the N-terminal region is intrinsically disordered and argue for a role for ID regions as integrators of signaling leading to tight regulation of the neuronal differentiation activity of Ngn2. Intrinsically disordered regions may well be enriched in post-translational modifications [26], making them ideal for integration of different signaling events and post-translational mechanisms of regulation. Such regulation is critical for normal development and the role of disordered regions highlights an alternative to the more widely established mechanism of switching between rigidly structured forms upon post-translational modification. Our data support our previous findings that it is the number, and not position, of phosphorylation sites available that controls Ngn2 neuronal differentiation activity [38,39]. This is similar to another process involving cell cycle regulation in the process of differentiation, namely the role of the Ste5 protein in MAP Kinase signaling in yeast [53].

\section{Conclusions}

Phosphorylation at serine-proline (SP) sites in Ngn2 occurs in both the $\mathrm{N}$ - and $\mathrm{C}$-terminal regions, located either side of the bHLH domain, and this phosphorylation does not alter the intrinsic stability of Ngn2 protein. Multi-site phosphorylation of SP sites inhibits the neuronal differentiation activity of Ngn2 protein, but it is the total number of phospho-sites available, rather than their precise sequence location or approximate location within a particular domain within the Ngn2 protein, that controls the ability of Ngn2 to drive neuronal differentiation in vivo in Xenopus embryos. We find that the $\mathrm{N}$-and $\mathrm{C}$-terminal regions of Ngn2 are intrinsically disordered and we have taken advantage of the disordered nature of the mNgn2 protein, and the ability to gain structural information about the N-terminal domain in particular, to observe phosphorylation by cyclinA/CDK2 kinase in vitro on an intrinsically disordered protein using protein NMR.

\section{Methods}

\section{Animal care}

Xenopus laevis were housed, bred, and treated according to the guidelines approved by the UK home office under the animal (Scientific Procedures) Act 1986. All animal work has been carried out under UK Home Office Licence and has passed an Institutional ethical review committee assessment, undertaken by the Animal Welfare and Ethical Review Committee (AWERC) at the University of Cambridge.

\section{Cloning}

Point-mutant constructs were made by site-directed mutagenesis (Stratagene) and cloned into pCS2+ as described previously $[28,35]$. Subcloning was carried out using standard methods.

\section{GST-tagged Ngn2}

A DNA construct of mNgn2, codon optimised for bacterial expression, was produced by Genecust (Luxembourg) in a pUC vector. This was placed into the pGEX (Nterminal GST-tagging [54]) vector by subcloning by restriction digest and ligation [55]. 


\section{In vitro translation}

In vitro translation was carried out using the $\mathrm{TNT}^{\bullet} \mathrm{SP} 6$ quick coupled transcription/translation system (Promega), in the presence of ${ }^{35} \mathrm{~S}$-methionine (GE Healthcare), according to the manufacturer's instructions.

\section{In vitro transcription of RNA}

RNA for microinjection (mRNA) or as an antisense probe for in situ hybridization was transcribed in vitro using constructs with a linearised pCS2+ vector template. Transcription was performed as described previously [38] using either the SP6 mMessage mMachine kit (Ambion) for mRNA or T3 polymerase (Roche) for antisense probe. Digoxigenin (DIG) labelling of the antisense probe was performed as described previously [38].

\section{Xenopus extracts}

Activated mitotic egg extract was prepared as described previously [35].

\section{Degradation assays}

Degradation assays were carried out as described previously [28,35,37].

\section{In situ hybridization}

In situ hybridization was carried out as described previously using neural $\beta$-tubulin antisense RNA as a probe $[38,39]$.

\section{Quantitative PCR}

Quantitative real-time PCR (qPCR) was performed as described previously [38]. Briefly, Xenopus embryos were injected with $20 \mathrm{pg}$ of mRNA at the 1 cell-stage and embryos were allowed to develop to Nieuwkoop and Faber stage 15 [56]. Samples were pooled such that 5 embryos for each condition underwent mRNA extraction with the RNeasy Mini kit (Qiagen) according to manufacturer's instructions. Reverse transcription to form cDNA was performed with oligodT primers and the Transcriptor High Fidelity cDNA Synthesis kit (Roche) according to manufacturer's instructions.

\section{Clustal W2 sequence alignment}

Clustal W2 analysis was carried out to align protein sequences [57].

\section{Protein disorder prediction}

Protein sequences were submitted to PONDR-FIT (available from www.DisProt.org/pondr-fit.php, [42]), DISOPRED2 (http://bioinf.cs.ucl.ac.uk/disopred/, [43]) and FoldIndex (http://bip.weizmann.ac.il/fldbin/findex, [44]) for disorder prediction.

\section{Secondary structure prediction}

Secondary Structure Propensity (SSP, [46]) along the mNgn2 sequence was calculated based on the available CA and CB chemical shifts from NMR data.

\section{Protein purification}

GST-mNgn2 was expressed in BL21 (DE3) cells transformed with ampicillin-resistant plasmids and grown in M9-based semi-rich medium (M9 medium (50 mM $\mathrm{Na}_{2} \mathrm{HPO}_{4}, 15 \mathrm{mM} \mathrm{KH} \mathrm{PO}_{4}, 8.5 \mathrm{mM} \mathrm{NaCl}$ ) supplemented with MEM, $1 \mathrm{mM} \mathrm{MgSO}_{4}, 100 \mu \mathrm{M} \mathrm{CaCl}_{2}, 1 \mathrm{~g} \mathrm{l}^{-1}{ }^{15} \mathrm{~N}$ $\mathrm{NH}_{4} \mathrm{Cl}, 2 \mathrm{~g} \mathrm{l}^{-1}{ }^{13} \mathrm{C}_{6}$-D-glucose (when ${ }^{13} \mathrm{C}$ labelling required, otherwise $4 \mathrm{~g} \mathrm{l}^{-1}$ unlabelled glucose (Sigma) used), $0.7 \mathrm{~g} \mathrm{l}^{-1}$ Isogro ${ }^{13} \mathrm{C},{ }^{15} \mathrm{~N}$ powder growth medium (Sigma), $100 \mu \mathrm{g} \mathrm{ml}^{-1}$ ampicillin) at $37^{\circ} \mathrm{C}$ to an $\mathrm{OD}_{600}$ of 0.6 . Protein expression was induced with $0.4 \mathrm{mM}$ IPTG at $20^{\circ} \mathrm{C}$ overnight. Harvested cells were lysed using lysozyme and sonication. Proteins were purified on a glutathione-bead containing column (Amersham) using an AKTA FPLC purifier (GE Healthcare) and eluted by cleavage of the GST tag from the protein using PreScission Protease (GE Healthcare) overnight at $4^{\circ} \mathrm{C}$ and elution in $1 \times \mathrm{PBS}$ supplemented with $2 \mathrm{mM}$ EDTA.

\section{In vitro phosphorylation of $\mathrm{mNgn} 2$}

$\mathrm{mNgn} 2$ was phosphorylated using recombinant CyclinA3/ Cdk2 [58] protein in $5 \mathrm{mM}$ ATP, $12.5 \mathrm{mM} \mathrm{MgCl}_{2}, 50 \mathrm{mM}$ HEPES pH 8.0, $55 \mathrm{mM} \mathrm{NaCl}, 5 \mathrm{mM} \mathrm{DTT}$, at $30^{\circ} \mathrm{C}$ for 5 hours [59] before passing through a G25 desalting resin in a Zeba spin column (Pierce) to buffer exchange into NMR buffer (50 mM Tris, $25 \mathrm{mM} \mathrm{NaCl}, 2.5 \mathrm{mM}$ EDTA and 2 mM DTT, pH 6.8).

\section{NMR}

$1 \mathrm{mM} \mathrm{D}_{4}$-TMSP (TriMethyl Silyl Propionate), used as a proton chemical shift internal reference $(0 \mathrm{ppm}$ or part per million), and $5 \% \mathrm{D}_{2} \mathrm{O}$ were added to protein samples. $\left[{ }^{1} \mathrm{H},{ }^{15} \mathrm{~N}\right]$ HSQC $2 \mathrm{D}$ spectra were recorded at $277 \mathrm{~K}$ on a Bruker 600 spectrometer equipped with a triple resonance cryogenic probehead (Bruker, Karlsruhe, Germany). Assignment was performed on a sample of doubly labelled protein at $150 \mu \mathrm{M}$, using classical pairs of 3D experiments. Spectra were processed using Bruker TOPSPIN 2.1 (Bruker, Karlsruhe, Germany). Peak picking was performed using Sparky (T. D. Goddard and D. G. Kneller, SPARKY 3, University of California, San Francisco).

\section{Availability of supporting data}

The data sets supporting the results of this article are included within the article and in its additional files. NMR datasets for $2 \mathrm{D}$ and $3 \mathrm{D}$ experiments are labelled as "2DNMR" and "3DNMR" respectively. 


\section{Additional files}

Additional file 1: Figure S1. SP sites are conserved in the C-terminal domain. Ngn2 protein sequences from the NCBI database were aligned using ClustalW2. The bHLH domain is indicated by the green box and SP sites conserved in over half of all species are indicated by the red boxes.

Additional file 2: Figure S2. SP site XNgn2 mutants schematic. Illustration of the various SP site mutants of XNgn2 used in this study.

Additional file 3: 2D NMR dataset. Raw data for 2D NMR experiments. Additional file 4: Table S1. $m$ Ngn2 $C A$ and $C B$ chemical shifts. Available CA and CB chemical shifts for visible residues.

Additional file 5: 3D NMR dataset. Raw data for 3D NMR experiments.

\section{Abbreviations}

Ngn2: Neurogenin2; x: Xenopus laevis; m: Mus musculus; h: Homo sapiens; bHLH: Basic Helix-Loop-Helix; ID: Intrinsic disorder; IVT: in vitro translation; pl: Isoelectric point.

\section{Competing interests}

The authors declare that they have no competing interests.

\section{Authors' contributions}

GM carried out degradation assays and bioinformatic analysis. $\mathrm{CH}$ carried out in situ hybridizations and $\mathrm{qPCR}$ analysis. GM and IL purified protein and carried out the NMR studies, and IL analysed the data. AP and GL conceived the study, and participated in its design and coordination. GM, CH, IL and AP wrote the manuscript. All authors have read and approved the final manuscript.

\section{Acknowledgements}

We thank lan Horan and Alison Jones for technical assistance, and Laura Itzhaki for helpful discussions. We thank Helen Wise for preliminary data leading up to this study. This work was supported by MRC Research Grant G0700758 (AP), a Cancer Research UK Studentship (CH) and an MRC DTA Studentship (GM). Support was also received (IL) from the TGE RMN THC (FR-3050, France). We acknowledge support for international collaboration by a BQR fellowship (GM) from Lille North of France University. The NMR facilities were funded by the Région Nord, CNRS, Pasteur Institute of Lille, European Community (FEDER), French Research Ministry and the University of Sciences and Technologies of Lille 1.

\section{Author details}

${ }^{1}$ Department of Oncology, MRC/Hutchison Research Centre, University of Cambridge, Cambridge Biomedical Campus, Cambridge CB2 OXZ, UK. ${ }^{2}$ CNRS, Université de Lille 1, UMR 8576 Villeneuve d'Ascq, France. ${ }^{3}$ Current address: Center for Regenerative and Developmental Biology, Department of Biology, Tufts University, 200 Boston Avenue, Medford, MA 02155, USA. ${ }^{4}$ Current address: The Gurdon Institute, University of Cambridge, Tennis Court Road, Cambridge CB2 1QN, UK.

Received: 11 July 2014 Accepted: 18 October 2014

Published online: 06 November 2014

\section{References}

1. Takahashi K, Yamanaka S: Induction of pluripotent stem cells from mouse embryonic and adult fibroblast cultures by defined factors. Cell 2006, 126(4):663-676.

2. Russo S, Tomatis D, Collo G, Tarone G, Tato F: Myogenic conversion of NIH3T3 cells by exogenous MyoD family members: dissociation of terminal differentiation from myotube formation. J Cell Sci 1998, 111(Pt 6):691-700.

3. Zhou Q, Brown J, Kanarek A, Rajagopal J, Melton DA: In vivo reprogramming of adult pancreatic exocrine cells to beta-cells. Nature 2008, 455(7213):627-632.

4. Prabakaran S, Lippens G, Steen H, Gunawardena J: Post-translational modification: nature's escape from genetic imprisonment and the basis for dynamic information encoding. Wiley Interdiscip Rev Syst Biol Med 2012, 4(6):565-583.
5. Fode C, Gradwohl G, Morin X, Dierich A, LeMeur M, Goridis C, Guillemot F: The bHLH protein NEUROGENIN 2 is a determination factor for epibranchial placode-derived sensory neurons. Neuron 1998, 20(3):483-494.

6. Ma Q, Fode C, Guillemot F, Anderson DJ: Neurogenin1 and neurogenin2 control two distinct waves of neurogenesis in developing dorsal root ganglia. Genes Dev 1999, 13(13):1717-1728.

7. Korzh V, Strahle U: Proneural, prosensory, antiglial: the many faces of neurogenins. Trends Neurosci 2002, 25(12):603-605.

8. Sun Y, Nadal-Vicens M, Misono S, Lin MZ, Zubiaga A, Hua X, Fan G, Greenberg ME: Neurogenin promotes neurogenesis and inhibits glial differentiation by independent mechanisms. Cell 2001, 104(3):365-376.

9. Heng J, Nguyen L, Castro DS, Zimmer C, Wildner H, Armant O, SkowronskaKrawczyk D, Bedogni F, Matter JM, Hevner R, Guillemot F: Neurogenin 2 controls cortical neuron migration through regulation of Rnd2. Nature 2008, 455(7209):114-118

10. Falk A, Holmstrom N, Carlen M, Cassidy R, Lundberg C, Frisen J: Gene delivery to adult neural stem cells. Exp Cell Res 2002, 279(1):34-39.

11. Zhang Y, Pak C, Han Y, Ahlenius H, Zhang Z, Chanda S, Marro S, Patzke C, Acuna C, Covy J, Xu W, Yang N, Danko T, Chen L, Wernig M, Südhof TC: Rapid single-step induction of functional neurons from human pluripotent stem cells. Neuron 2013, 78(5):785-798.

12. Mattar P, Britz O, Johannes C, Nieto M, Ma L, Rebeyka A, Klenin N, Polleux F, Guillemot F, Schuurmans C: A screen for downstream effectors of Neurogenin2 in the embryonic neocortex. Dev Biol 2004, 273(2):373-389.

13. Koyano-Nakagawa N, Wettstein D, Kintner C: Activation of Xenopus genes required for lateral inhibition and neuronal differentiation during primary neurogenesis. Mol Cell Neurosci 1999, 14(4-5):327-339.

14. Seo S, Richardson GA, Kroll KL: The SWI/SNF chromatin remodeling protein Brg1 is required for vertebrate neurogenesis and mediates transactivation of Ngn and NeuroD. Development 2005, 132(1):105-115.

15. Dyson HJ, Wright PE, Scheraga HA: The role of hydrophobic interactions in initiation and propagation of protein folding. Proc Natl Acad Sci U S A 2006, 103(35):13057-13061.

16. Dunker AK, Obradovic Z: The protein trinity-linking function and disorder. Nat Biotechnol 2001, 19(9):805-806.

17. Gast K, Damaschun H, Eckert K, Schulze-Forster K, Maurer HR, Muller-Frohne M, Zirwer D, Czarnecki J, Damaschun G: Prothymosin alpha: a biologically active protein with random coil conformation. Biochemistry 1995, 34(40):13211-13218.

18. Weinreb PH, Zhen W, Poon AW, Conway KA, Lansbury PT Jr: NACP, a protein implicated in Alzheimer's disease and learning, is natively unfolded. Biochemistry 1996, 35(43):13709-13715.

19. Brown CJ, Takayama S, Campen AM, Vise P, Marshall TW, Oldfield CJ, Williams CJ, Dunker AK: Evolutionary rate heterogeneity in proteins with long disordered regions. J Mol Evol 2002, 55(1):104-110.

20. Ward JJ, Sodhi JS, McGuffin LJ, Buxton BF, Jones DT: Prediction and functional analysis of native disorder in proteins from the three kingdoms of life. J Mol Biol 2004, 337(3):635-645.

21. Dyson HJ, Wright PE: Coupling of folding and binding for unstructured proteins. Curr Opin Struct Biol 2002, 12(1):54-60.

22. Dunker AK, Brown CJ, Lawson JD, lakoucheva LM, Obradovic Z: Intrinsic disorder and protein function. Biochemistry 2002, 41(21):6573-6582.

23. Hager GL, McNally JG, Misteli T: Transcription dynamics. Mol Cell 2009 35(6):741-753.

24. Michel D: Fine tuning gene expression through short DNA-protein binding cycles. Biochimie 2009, 91(7):933-941

25. Gsponer J, Futschik ME, Teichmann SA, Babu MM: Tight regulation of unstructured proteins: from transcript synthesis to protein degradation. Science 2008, 322(5906):1365-1368.

26. lakoucheva LM, Radivojac P, Brown CJ, O'Connor TR, Sikes JG, Obradovic Z, Dunker AK: The importance of intrinsic disorder for protein phosphorylation. Nucleic Acids Res 2004, 32(3):1037-1049.

27. Dunker AK, Lawson JD, Brown CJ, Williams RM, Romero P, Oh JS, Oldfield CJ, Campen AM, Ratliff CM, Hipps KW, Ausio J, Nissen MS, Reeves R, Kang C, Kissinger CR, Bailey RW, Griswold MD, Chiu W, Garner EC, Obradovic Z: Intrinsically disordered protein. J Mol Graph Model 2001, 19(1):26-59.

28. Vosper JM, Fiore-Heriche CS, Horan I, Wilson K, Wise H, Philpott A: Regulation of neurogenin stability by ubiquitin-mediated proteolysis. Biochem J 2007, 407(2):277-284.

29. Wright PE, Dyson HJ: Linking folding and binding. Curr Opin Struct Biol 2009, 19(1):31-38 
30. Bertrand N, Castro DS, Guillemot F: Proneural genes and the specification of neural cell types. Nat Rev Neurosci 2002, 3(7):517-530.

31. Longo A, Guanga GP, Rose RB: Crystal structure of E47-NeuroD1/beta2 bHLH domain-DNA complex: heterodimer selectivity and DNA recognition. Biochemistry 2008, 47(1):218-229.

32. Wendt $H$, Thomas RM, Ellenberger T: DNA-mediated folding and assembly of MyoD-E47 heterodimers. J Biol Chem 1998, 273(10):5735-5743.

33. Aguado-Llera D, Goormaghtigh E, de Geest N, Quan XJ, Prieto A, Hassan BA, Gomez J, Neira JL: The basic helix-loop-helix region of human neurogenin 1 is a monomeric natively unfolded protein which forms a "fuzzy" complex upon DNA binding. Biochemistry 2010, 49(8):1577-1589.

34. Kitzmann M, Vandromme M, Schaeffer V, Carnac G, Labbe JC, Lamb N, Fernandez A: cdk1- and cdk2-mediated phosphorylation of MyoD Ser200 in growing C2 myoblasts: role in modulating MyoD half-life and myogenic activity. Mol Cell Biol 1999, 19(4):3167-3176.

35. Vosper JM, McDowell GS, Hindley CJ, Fiore-Heriche CS, Kucerova R, Horan I Philpott A: Ubiquitylation on canonical and non-canonical sites targets the transcription factor neurogenin for ubiquitin-mediated proteolysis. J Biol Chem 2009, 284(23):15458-15468.

36. McDowell GS, Hardwick $L$, Philpott A: Complex domain interactions regulate stability and activity of closely related proneural transcription factors. Biochem Biophys Res Commun 2014, 450(4):1283-1290.

37. McDowell GS, Kucerova R, Philpott A: Non-canonical ubiquitylation of the proneural protein Ngn2 occurs in both Xenopus embryos and mammalian cells. Biochem Biophys Res Commun 2010, 400(4):655-660.

38. Ali F, Hindley C, McDowell G, Deibler R, Jones A, Kirschner M, Guillemot F, Philpott A: Cell cycle-regulated multi-site phosphorylation of Neurogenin 2 coordinates cell cycling with differentiation during neurogenesis. Development 2011, 138(19):4267-4277.

39. Hindley C, Ali F, McDowell G, Cheng K, Jones A, Guillemot F, Philpott A: Post-translational modification of Ngn2 differentially affects transcription of distinct targets to regulate the balance between progenitor maintenance and differentiation. Development 2012, 139(10):1718-1723.

40. Ma YC, Song MR, Park JP, Henry Ho HY, Hu L, Kurtev MV, Zieg J, Ma Q, Pfaff SL, Greenberg ME: Regulation of motor neuron specification by phosphorylation of neurogenin 2. Neuron 2008, 58(1):65-77.

41. Farah MH, Olson JM, Sucic HB, Hume Rl, Tapscott SJ, Turner DL: Generation of neurons by transient expression of neural bHLH proteins in mammalian cells. Development 2000, 127(4):693-702.

42. Xue B, Dunbrack RL, Williams RW, Dunker AK, Uversky VN: PONDR-FIT: a meta-predictor of intrinsically disordered amino acids. Biochim Biophys Acta 2010, 1804(4):996-1010.

43. Ward JJ, McGuffin $\sqcup$, Bryson K, Buxton BF, Jones DT: The DISOPRED server for the prediction of protein disorder. Bioinformatics 2004, 20(13):2138-2139.

44. Prilusky J, Felder CE, Zeev-Ben-Mordehai T, Rydberg EH, Man O, Beckmann JS, Silman I, Sussman JL: FoldIndex: a simple tool to predict whether a given protein sequence is intrinsically unfolded. Bioinformatics 2005 , 21(16):3435-3438.

45. Cavanagh J, Fairbrother WJ, Palmer AG, Skelton NJ, Rance M: Protein NMR Spectroscopy: Principles and Practice. Waltham MA: Elsevier Science; 2010.

46. Marsh JA, Singh VK, Jia Z, Forman-Kay JD: Sensitivity of secondary structure propensities to sequence differences between alpha- and gamma-synuclein: implications for fibrillation. Protein Sci 2006, 15(12):2795-2804

47. Landrieu I, Lacosse L, Leroy A, Wieruszeski JM, Trivelli X, Sillen A, Sibille N, Schwalbe $H$, Saxena K, Langer T, Lippens G: NMR analysis of a Tau phosphorylation pattern. J Am Chem Soc 2006, 128(11):3575-3583.

48. Theillet FX, Smet-Nocca C, Liokatis S, Thongwichian R, Kosten J, Yoon MK, Kriwacki RW, Landrieu I, Lippens G, Selenko P: Cell signaling, post-translational protein modifications and NMR spectroscopy. J Biomol NMR 2012, 54(3):217-236.

49. Bienkiewicz EA, Lumb KJ: Random-coil chemical shifts of phosphorylated amino acids. J Biomol NMR 1999, 15(3):203-206.

50. Wishart DS, Bigam CG, Yao J, Abildgaard F, Dyson HJ, Oldfield E, Markley JL, Sykes BD: $1 \mathrm{H}, 13 \mathrm{C}$ and $15 \mathrm{~N}$ chemical shift referencing in biomolecular NMR. J Biomol NMR 1995, 6(2):135-140.

51. Vierbuchen $T$, Ostermeier A, Pang ZP, Kokubu $Y$, Sudhof TC, Wernig M: Direct conversion of fibroblasts to functional neurons by defined factors. Nature 2010, 463(7284):1035-1041.

52. Tao H, Liu W, Simmons BN, Harris HK, Cox TC, Massiah MA: Purifying natively folded proteins from inclusion bodies using sarkosyl, Triton X-100, and CHAPS. Biotechniques 2010, 48(1):61-64.
53. Strickfaden SC, Winters MJ, Ben-Ari G, Lamson RE, Tyers M, Pryciak PM: A mechanism for cell-cycle regulation of MAP kinase signaling in a yeast differentiation pathway. Cell 2007, 128(3):519-531.

54. Kaelin WG Jr, Krek W, Sellers WR, DeCaprio JA, Ajchenbaum F, Fuchs CS, Chittenden T, Li Y, Farnham PJ, Blanar MA, Livingston DM, Flemington EK: Expression cloning of a cDNA encoding a retinoblastoma-binding protein with E2F-like properties. Cell 1992, 70(2):351-364.

55. Sambrook J, Russell DW: Molecular Cloning: A Laboratory Manual. Cold Spring Harbor NY: Cold Spring Harbor Laboratory Press; 2001.

56. Nieuwkoop PD, Faber J: Normal Table of Xenopus Laevis (Daudin): A Systematical and Chronological Survey of the Development from the Fertilized Egg Till the End of Metamorphosis. New York NY: Garland Publishing, Incorporated; 1994.

57. Chenna R, Sugawara H, Koike T, Lopez R, Gibson TJ, Higgins DG, Thompson JD: Multiple sequence alignment with the Clustal series of programs. Nucleic Acids Res 2003, 31(13):3497-3500.

58. Brown NR, Noble ME, Endicott JA, Johnson LN: The structural basis for specificity of substrate and recruitment peptides for cyclin-dependent kinases. Nat Cell Biol 1999, 1(7):438-443.

59. Amniai L, Barbier P, Sillen A, Wieruszeski JM, Peyrot V, Lippens G, Landrieu I: Alzheimer disease specific phosphoepitopes of Tau interfere with assembly of tubulin but not binding to microtubules. FASEB J 2009, 23(4):1146-1152.

\section{doi:10.1186/s12858-014-0024-3}

Cite this article as: McDowell et al:: Phosphorylation in intrinsically disordered regions regulates the activity of Neurogenin2. BMC Biochemistry 2014 15:24.

\section{Submit your next manuscript to BioMed Central and take full advantage of:}

- Convenient online submission

- Thorough peer review

- No space constraints or color figure charges

- Immediate publication on acceptance

- Inclusion in PubMed, CAS, Scopus and Google Scholar

- Research which is freely available for redistribution 